\section{The innovative new autoclave}

Eschmann has recently launched its new Little Sister SES 3020B autoclave - a versatile option for professionals who want to keep at the very cutting-edge of infection control.

An innovatively designed system that can comfortably fit on a standard work surface,

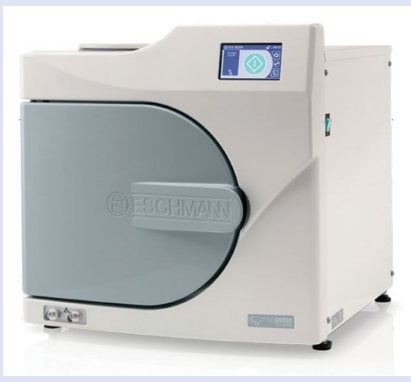
the new autoclave features a large, 23-litre capacity chamber and can process up to $6 \mathrm{~kg}$ of instruments. Plus, due to its dedicated long instrument tray, it can process instruments up to $370 \mathrm{~mm}$ in length.

The system boasts a number of features making it a musthave for the modern professional, including the ability to switch between ' $\mathrm{N}$ ' type and 'B' type cycles to accommodate every type of load. Furthermore, inbuilt multiple processors guarantee the sterility of each cycle, keeping compliance at the forefront of your infection control process.

To find out more about the state-of-the-art Little Sister SES 3020B, contact the team at Eschmann.

For more information on the highly effective and affordable range of decontamination equipment and products from Eschmann, visit www.eschmann.co.uk or call 01903875787.

\section{Perfect control over your impressions}

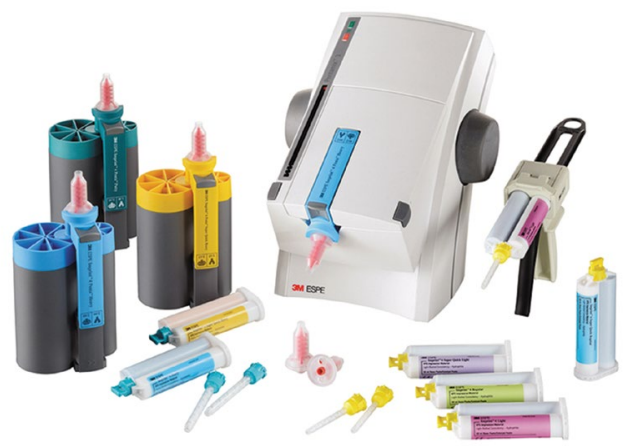

For eight years in a row, $3 \mathrm{M}$ Imprint 4 VPS Impression Material has been an award-winner. In 2021, it was once again given the title of 'Best VPS Impression Material' at the Dental Advisor awards!

So, what makes this impression material a winner time and time again?

3M Imprint 4 VPS Impression Material has unique chemistry that ensures that it doesn't start to set until working time is over. This means you always have sufficient time to load and seat the tray without the stressful race against the clock.

Plus, 3M Imprint 4 VPS Impression Material offers faster setting times when compared to other leading VPS impression materials, helping to boost patient comfort and provide more accurate results.

For more information, call 08458734066 or visit www.3m. co.uk/dental.

$3 \mathrm{M}$ and Imprint are trademarks of the 3M Company.

\section{Award-winning excellence}

Carestream Dental is pleased to announce that the CS 9600 CBCT system has earned the coveted Cellerant Best of Class Technology Award for the third year in a row.

This means that the CS 9600 is the only extraoral imaging system to have been recognised by the award more than once - a fantastic achievement that proves how extraordinary the system really is.

Offering scalable, 5 -in-1 imaging and an outstanding level of precision and clarity, the system is versatile to every indication no matter how complex. Plus, with additional features such as AI-powered patient positioning, a dedicated metal artifact reduction module and low-dose imaging, it's easy to see why the CS 9600 reigns supreme.

For more information, contact Carestream Dental on 0800169 9692 or visit www.carestreamdental.co.uk.

\section{A happy team is a better team}

Happiness among staff at work is linked to increased productivity, enhanced teamwork and improved patient experiences. Help your team overcome the challenges of the past year by bringing a little joy to your practice.

A major enabler to

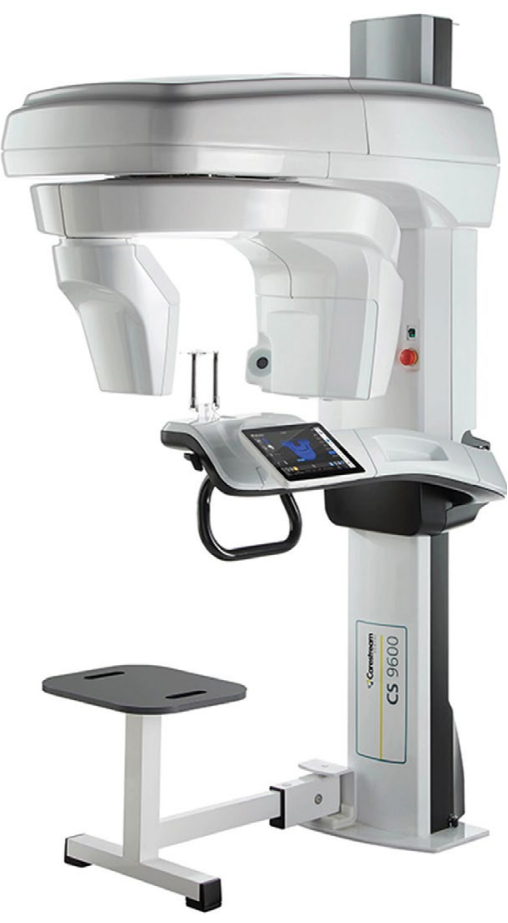
job satisfaction is career development, so why not support your colleagues in their ambitions by taking the whole team to the British Dental Conference and Dentistry Show. Not only will there be education and enhanced CPD for all delivered by world-class speakers, but also this will be accompanied by an extensive trade exhibition demonstrating the latest innovations to re-inspire delegates.

This will also be a great opportunity to enjoy some social time with the team and reconnect after a difficult few months. After all, a happy team is a better team.

The British Dental Conference and Dentistry Show will be held on Friday 21 and Saturday 22 May 2022, Birmingham NEC, co-located with DTS.

For more information, visit www.thedentistryshow.co.uk, call 02073485270 or email dentistry@closerstillmedia.com. 